\title{
Effects of ziclague phytotherapic associated with kinesitherapy on the equine foot of children with spastic cerebral palsy
}

\author{
Jéssika da Silva Martins ${ }^{1}$, Marina Ortega Golin² \\ ${ }^{1}$ Centro Universitário Saúde ABC, Santo André (SP), Brazil; ${ }^{2}$ Centro Universitário Saúde ABC (FMABC), Santo André (SP), Brazil.
}

\begin{abstract}
Background: Spasticity is the most common disorder of Cerebral Palsy (CP) and has the characteristics of decreased active movement, elastic hypertonia and hyperreflexia. Because of this, one of the main purposes of treatment is to decrease hypertonia. Thus, the herbal medicine Ziclague $\AA$, having an antispasmodic action, may offer a new possibility in addition to physiotherapy. Objective: Verify the effects of the application of the herbal medicine Ziclague on hypertonia of the sural triceps muscle of children with spastic CP. Methods: Ten children, between one and seven years of age, received application of Ziclague $\AA$ spray on the triceps sural muscle before the physiotherapy sessions, during the period of twelve weeks. Evaluations were performed using the Modified Ashworth Scale (MAS), Durigon Protocol (DP) and goniometry, before and after application on the first day, after four weeks and at the end of twelve weeks. The four evaluations were compared. Results: After twelve weeks the results were more evident, with a decrease in hypertonia of the right lower limb (RLL) and left lower limb (LLL) verified by MAS $(p=0.06$ and $p=0.13)$, and by the DP $(p=0.003$ and $p=0.007)$. Goniometry showed increased range of motion for dorsiflexion of the RLL $(p=0.002)$ and $L L L(p=0.111)$. Conclusion: The use of Ziclague ${ }^{\circledR}$ associated with physiotherapy had a positive effect in decreasing hypertonia of the sural triceps muscle and in increasing the ankle dorsiflexion range of motion.

Keywords: Cerebral Palsy; Muscular Spasticity; Alpinia; Phytotherapy; Physiotherapy.
\end{abstract}

\section{BACKGROUND}

Cerebral palsy (CP) or chronic non-progressive encephalopathy is due to a brain injury in the early stage of development ${ }^{(1)}$. Its origin can occur in the prenatal, perinatal and postnatal periods ${ }^{(2)}$. Its main impairment is motor function, causing changes in body biomechanics and contributing to bone deformities $^{(3)}$. It is possible to associate other brain injuries, resulting in associated deficits such as intellectual disability, seizures, sensory changes, dysfunctions in speech, hearing and swallowing ${ }^{(4)}$.

Although there is no international consensus etiology, there is a grouping of the most common causes according to the period of the injury. Prenatal period: congenital malformations, infections, epilepsy, maternal hyperthyroidism, placental disorders and multiple pregnancy. In the perinatal period: premature births, low weight, hypoxia or perinatal asphyxia and hyperbilirubinemia.

Postnatal period: traumatic brain injury, metabolic encephalopathies, intracranial hemorrhage and intracranial tumors ${ }^{(2)}$. Its incidence is two to three per 1000 live births, in developed countries and in developing countries it can reach up to seven per 1000 live births. In Brazil, the estimate is 20,000 new cases of CP annually ${ }^{(1,2,5)}$.
The classification of motor dysfunction is related to the topography of the lesion, which includes: tetraparesis (involvement of the four limbs), diparesis (greater involvement in the lower limbs in relation to the upper limbs) and hemiparesis (involvement of a hemibody). And by the type of tonic alteration, which are: pyramidal or spastic; extrapyramidal or dyskinetic, and may be atetoid, choreic or dystonic; non-toxic; hypotonic and mixed $^{(1,6)}$. The degree of motor impairment and the existence of associated disorders, such as tendon retractions and skeletal deformities, are fundamental factors in determining the prognosis of the child with PC. However, the availability and quality of treatment are also extremely important for a favorable outcome ${ }^{(1,5)}$. Spasticity is the most common disorder and its characteristics are the decrease in active movement, elastic hypertonia, which is the increase in muscle resistance to passive stretching, with dependent speed and hyperreflexia, caused by the increase in the stretch reflex $^{(1,6)}$. Thus, the treatment modalities for spastic $\mathrm{CP}$ focus on reducing hypertonia to enable maximum functional potential and reduce secondary problems, such as shortening and contractures ${ }^{(5)}$. 
The treatment of spasticity includes oral medications such as: baclofen (also used intrathecally), clonazepam, dantrolene, tizanidine; local injections such as botulinum toxin and surgical procedures such as selective dorsal rhizotomy and orthopedic corrections. Likewise, the use of orthoses and kinesiotherapy ${ }^{(7)}$.

A recent additional resource is phytotherapy, which uses the active principle of plants. One of these possibilities is Alpinia zerumbet $(A z)$, which is a herbaceous plant, with great concentration in the Northeast of the country ${ }^{(8)}$

The active ingredient in $A z$ is popularly used as a diuretic, sedative and hypotensive. It also has an action on the modulation of calcium concentration, resulting in antispasmodic activity and relaxation of basal tone. Thus, it can present benefits in several dysfunctions, such as spasticity $^{(9)}$.

The use of $A z$ can be in the form of essential oil, which is the substance extracted from plants, mainly from their glands and cells. Its supply is directed to pharmaceutical and cosmetology industries. The essential oil is used in oral, nasal and transdermal ways. The latter offers a great option, as it does not have access to the digestive system and does not require hepatic metabolism $^{(10)}$

The herbal medicine Ziclague ${ }^{\circledR}$ concentrates the essential oil of $A z$ (EOAz) in spray and for topical use. Its mechanism of action is the blocking of L-type calcium channels and muscle ryanodine receptors, as its muscle target is the ryanodynamic receptor, which, together with actin, is responsible for the release and storage of calcium, resulting from the troponin $\mathrm{C}^{(11)}$. As a result, calcium ions dissociate from troponin $\mathrm{C}$ and deactivate tropomyosin cross-bridges, reducing muscle tension ${ }^{(8)}$.

There is also the hydrolysis of calciumATPase, which promotes the transport of calcium to the vesicles of the sarcoplasmic reticulum. Thus, excess calcium is removed, enabling the proper contraction-relaxation process ${ }^{(11)}$.

Because, with the reduction of the concentration of this ion present in the cytosol during reuptake, troponin is inhibited and crossbridges do not occur, promoting muscle relaxation and enabling the reduction of hypertonia ${ }^{(8)}$.

In addition, its effects also provide increased muscle flexibility, as they promote the modulation of type I and type III collagens, in their thickness and organization ${ }^{9}$. The easy application contributes to its use and because it is through the dermal route, it allows to specifically target spastic muscles. Therefore, it does not subject the child to a systemic treatment and offers few adverse effects $^{(8)}$

Thus, the Ziclague can offer a new possibility in addition to physiotherapy for the treatment of spasticity. Only a few studies were found in the literature that used the association of both resources, however, they showed positive effects in reducing hypertonia ${ }^{(12,13)}$. In the study of Cândido and Xavier-filho ${ }^{8}$, the use of Ziclague promoted a significant decrease in hypertonia in 38 children with CP. Two other surveys conducted by Cândido et al. ${ }^{(12)}$ and Cândido et al. ${ }^{(13)}$ showed that its use associated with kinesiotherapy sessions was effective in reducing hypertonia in the same profile of participants.

Anyway, the studies carried out to date point to the benefits that the use of the herbal medicine Ziclague can bring to the treatment of children with Spastic CP. However, due to the still small number, it becomes evident the importance of carrying out additional investigations to enable the determination of its real effectiveness and the variables that influence it.

Determining in this way the objective of the current study as: to verify the effects of the application of the herbal medicine Ziclague in the hypertonia of the triceps surae muscle of children with spastic CP.

\section{METHODS}

This cross-sectional study was carried out at the physiotherapy outpatient clinic of State Hospital Mário Covas de Santo André (SP), from September to November 2018, totaling twelve weeks.

Initially, twelve children diagnosed with spastic $\mathrm{CP}$ and aged between one and seven years were included in the research. However, only ten remained as two were disconnected from the physiotherapeutic treatment program of the hospital mentioned, due to absences during the collection period. All participants were functionally classified by the Gross Motor Function Classification System (GMFCS). Inclusion criteria were established: performing physical therapy treatment at the clinic mentioned, medical diagnosis of Cerebral Palsy, clinical diagnosis of Spasticity and prior signing of the Informed Consent Form by the person responsible.

And as exclusion criteria: non-collaboration of the child in the execution of assessment and treatment techniques, ankle joint deformity, muscle tissue retraction, plantar flexors that do not allow passive dorsiflexion at neutral or zero degrees, tissue retraction of the knee flexor muscles, which prevents full passive extension of the knee with the hip in a neutral position, previous orthopedic surgery 
for stretching the triceps surae muscle, application of botulinum toxin to the same muscle in the last six months, history of hypersensitivity or allergy to any of the components of the Ziclague formula and presenting hypotension.

All participants were included in the individual physiotherapeutic treatment program, according to Bobath Concept, with a twice-weekly frequency and 50-minute session duration. The intervention with the herbal medicine Ziclague in the triceps surae muscle was an additional resource and followed a protocol. It was applied 15 minutes before each session was started, under the direct supervision of the responsible researcher. The evaluations were performed before and after the first session using the Ziclague. And they were reapplied after four and twelve weeks, at the end of the physiotherapy session.

Regarding the procedures, to measure passive dorsiflexion range of motion (ROM) using goniometry, the children were placed in the supine position, with neutral hips and total knee extension, the fulcrum of the goniometer was positioned in alignment with the lateral malleolus, the fixed arm aligned with the lateral face of the fibula and the mobile arm followed the movement of the ankle in alignment with the fifth metatarsal. The starting angle was the plantar flexion at rest ${ }^{(14)}$.

For the graduation of hypertonia of the triceps surae muscle, it was adopted the Modified Ashworth Scale (MAS) ${ }^{(15)}$ and the Durigon Protocol (DP) ${ }^{(16)}$. For the application of both, the children were positioned in the same way as described above and the evaluator with one hand stabilized the distal third of the leg (distal tibial diaphysis), performed the slow passive dorsiflexion and plantar flexion of the ankle, identifying, the Maximum ROM of each participant. Then, it was performed the rapid passive movement, starting from the maximum plantar flexion until reaching the maximum dorsiflexion.
Phytotherapic applications occurred before all physiotherapy sessions, during the twelve weeks, following the directions for use present in the medicine leaflet. The dose was determined by age and topography, not exceeding the maximum dosage for each child. Participants were placed in prone position and sprayed on the triceps surae muscle.

This research was approved by the Research Ethics Committee of the faculty de Medicina do ABC, sob o $n^{\circ}$ 2.830.201/19.

\section{Statistical Analysis}

Qualitative variables were presented by absolute and relative frequency and quantitative variables by median and $25^{\text {th }}$ and $75^{\text {th }}$ percentile values, by means of the normality test of ShapiroWilk data $(p<0.05)$.

In all analyzes, MAS scores were adjusted in numerical sequence due to $1+$ becoming 2 and so on, successively for the other scores. To analyze the variables Goniometry, MAS and DP between moments, the Friedman test was used, with Dunn's post test. For all analyzes, the level of significance adopted was $p<0.05$. The statistical program used was Stata version 11.0.

\section{RESULTS}

The characterization of the participants is shown in table 1. Among the orthoses used, the most frequent was the $60 \%$ fixed suropodalic splint, followed by $30 \%$ thumb abductor with bar and $10 \%$ used the ground reaction suropodalic splint, Putti vest, band in shape of 8 and parapodium. Regarding medications, $50 \%$ used anticonvulsants, $20 \%$ anxiolytics and $10 \%$ other medications. The functional classification by the GMFCS is shown in Table 2.

Table 1. Sample characterization.

\begin{tabular}{lcc}
\hline Characteristics & $\mathrm{n}$ & $\%$ \\
\hline Gender & 4 & 40 \\
Male & 6 & 60 \\
Female & 5 & 50 \\
Motor diagnostics & 4 & 40 \\
Spastic Diparesis & 1 & 10 \\
Spastic Tetraparesis & Mean & Standard deviation \\
Spastic Hemiparesis & 4.1 & 2.02 \\
& 29.3 & 22.17 \\
Age (in years) & 1.8 & 0.42 \\
Duration of physiotherapy treatment (in months) & & \\
Ziclague dosage & & \\
\hline
\end{tabular}


The proposed physiotherapeutic treatment was based on the GMFCS level (table 2), aimed at the functional objective. To achieve it, some objectives were defined as minor. All children, regardless of functional level, were subjected to conducts aimed at adapting muscle tone and increasing extensibility, especially triceps surae muscle. For the latter, three repetitions of passive stretching were performed, with a maintenance time of 30 seconds, in each of the sessions.

Table 2. Gross Motor Function Classification System (GMFCS) of the participants.

\begin{tabular}{lll}
\hline GMFCS level & $\mathrm{n}$ & $\%$ \\
\hline I & 5 & 50 \\
II & 1 & 10 \\
III & 0 & 0 \\
IV & 3 & 30 \\
V & 1 & 10 \\
\hline
\end{tabular}

In level I children, two different functional objectives were established, one of which was to encourage gait with support or a device and the other, independence in gait on uneven floor. And the additional minor objectives were: increased hip and ankle mobility, stimulating straightening reactions, protection and balance in orthostatism, stimulating the transition from sedation to bipedal, increasing muscle strength of hip and knee extensors and hip abductors.

The level II child had the functional objective of walking on regular ground independently and the additional minor objectives were the same as those of level I, except: increased ankle mobility.

At Level IV, the functional objective was to stay in the sitting position without support and its additional smaller goals were: to increase paravertebral muscle strength and spine mobility; stimulate straightening reaction in sitting position; increase static control of the torso and shoulder girdle and provide benefits of orthostatism.

And the child at level $\mathrm{V}$ had the functional objective to stimulate cervical control and having as additional minor objectives: increase mobility of the spine and control of the shoulder girdle, stimulate the rolling and provide benefits of orthostatism.

The children were evaluated at four times, before using Ziclague (AUZ), after the first physical therapy session (A1SF), after one month of physical therapy (A1MF) and after three months of physical therapy (A3MF). Figures 1 and 2 show the spasticity graduation by MAS and show the relationship of the four moments, being, respectively, the right lower limb (RLL) and the left lower limb (LLL). In Table 1, it is observed that after applying the Ziclague, the percentage of RLL grades 2 and 4 decreased and the greatest reductions occurred after three months, with greater proportions of grade 1 , tending to be significant, with $p=0.06$

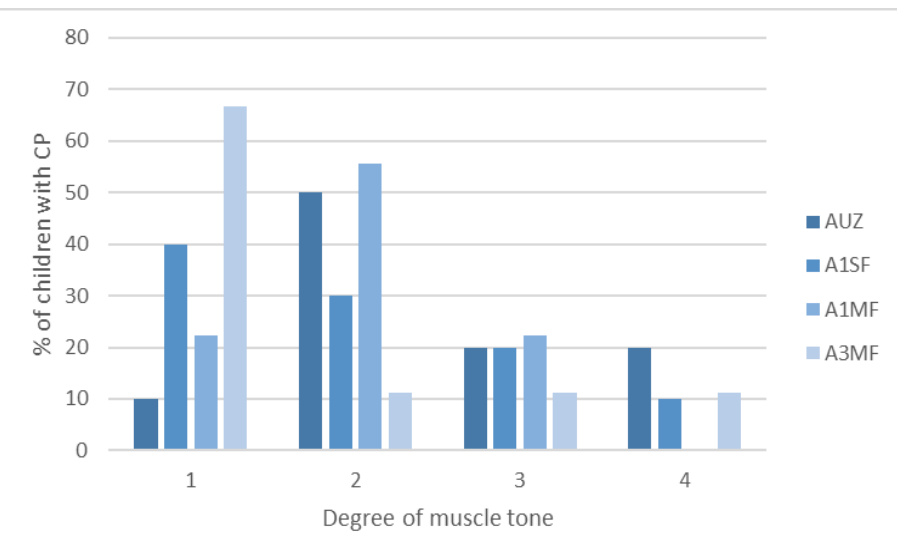

Figure 1. Graduation of spasticity of the triceps surae muscle of the right lower limb, using the Modified Ashworth Scale, according to the percentage of children with CP. AUZ, A1S, A1M, A3M. Friedman test and after Dunn test.

*Note: Friedman test and after Dunn test.

In figure 2, in turn, there is an oscillation in the severity of the graduation of LLL hypertonia, mainly in the evaluation after one month. However, when the final evaluation is observed, the concentration of graduation 1 was also higher, showing a decrease in tone. However, it did not reach statistical significance $(p=0.13)$. 


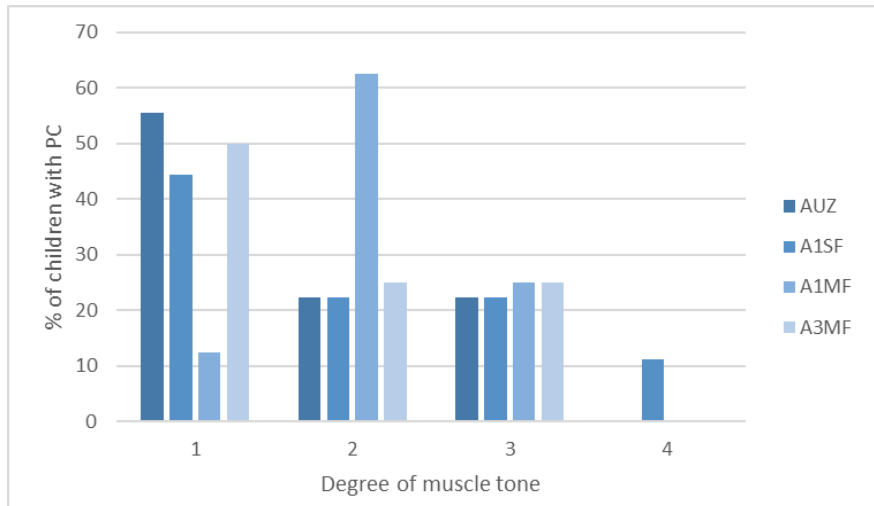

Figure 2. Graduation of spasticity of the triceps surae muscle of the left lower limb, using the Modified Ashworth Scale, according to the percentage of children with CP. AUZ, A1S, A1M, A3M.

"Note: Friedman test and after Dunn test.

Figures 3 and 4 show the values of the dorsiflexion goniometry of the RLL and LLL, respectively. In Figure 3 , the moment $\mathrm{A} 1 \mathrm{MF}$ presents the 25th percentile higher than the median of the moments AUZ and A1SF, showing an increase in the dorsiflexion angle. As well as, the moment A3MF, which had the 25th percentile equal to the median of the moment $\mathrm{A} 1 \mathrm{MF}$ and equal to the maximum value of the moment AUZ. The results showed significance when comparing the AUZ and A1MF moments and the AUZ and A3MF moments $(p=0.002)$. Figure 4 also shows the increase in the angulation of the AUZ and A3MF goniometry of the LLL, even with the initial dorsiflexion graduation greater than that of the RLL, however it did not reach statistical significance $(p=0.111)$.

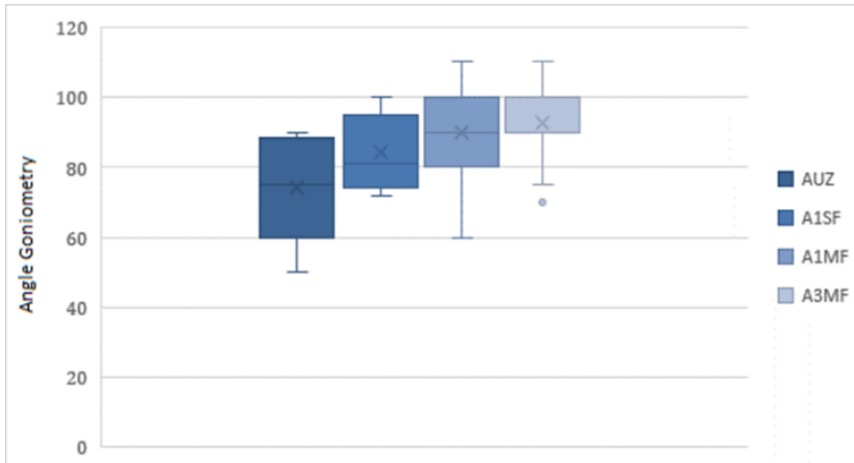

Figure 3. Degree of dorsiflexion goniometry of the right lower limb, AUZ, A1S, A1M, A3M. Shapiro-Wilk data normality test and between moments.

"Note: Friedman test and after Dunn test.

Figure 5 shows a decrease in the RLL spasticity when comparing AUZ and the other moments, presenting as the 75th percentile the same value as the 25th percentile of the AUZ situation, that is, the value 6 of tone graduation, showing significance $(p=$
0.003). Figure 6 also shows a decrease in LLL spasticity, less than in RLL, but also with statistical significance $(p=0.007)$.

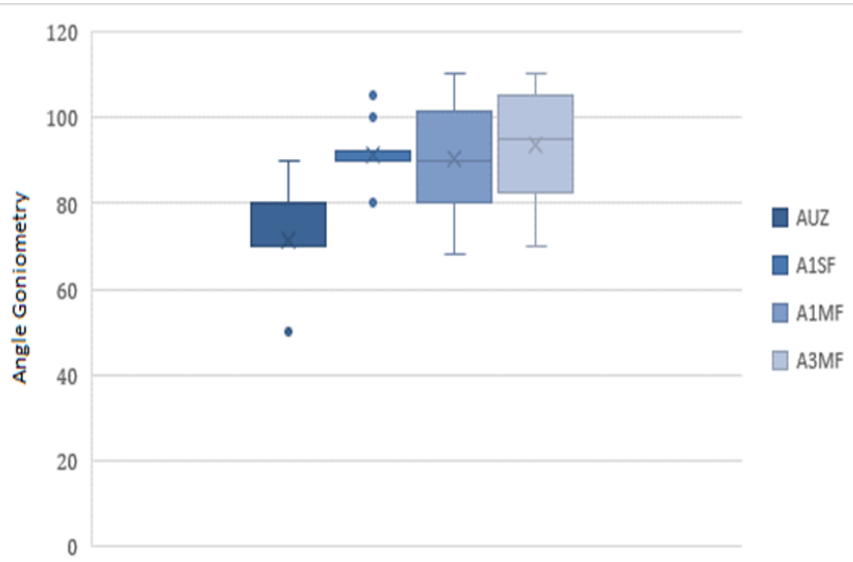

Figure 4. Degree of dorsiflexion goniometry of the left lower limb, AUZ, A1S, A1M, A3M. Shapiro-Wilk data normality test and between moments.

*Note: Friedman test and after Dunn test.

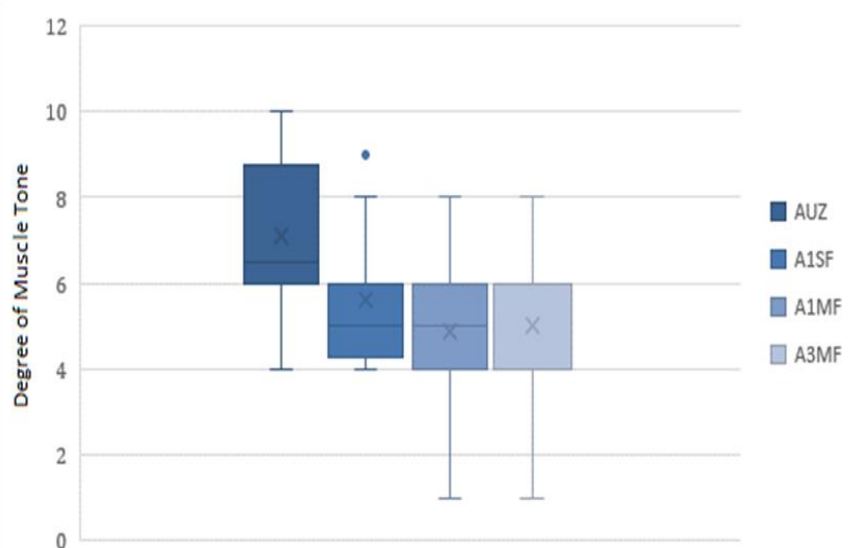

Figure 5. Degree of spasticity by the Durigon Protocol; reaction to passive stretching of the right lower limb; AUZ, A1S, A1M, A3M. Shapiro-Wilk data normality test; and between moments.

"Note: Friedman test and after Dunn test.

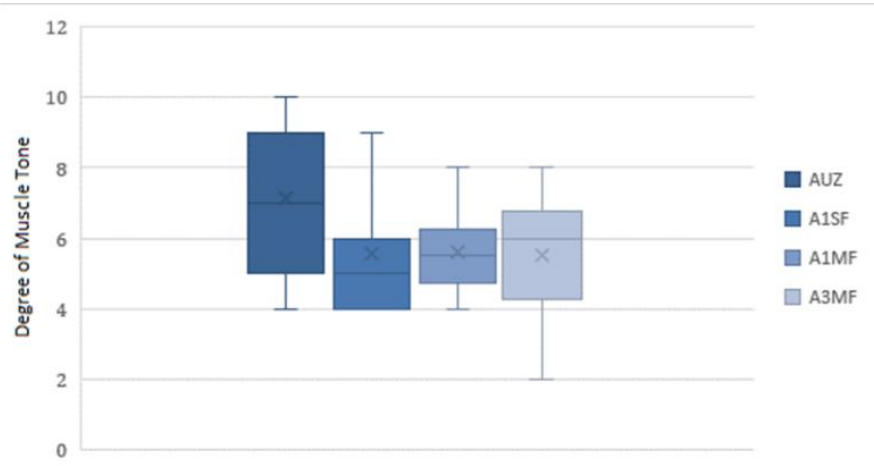

Figure 6. Degree of spasticity by the Durigon Protocol; reaction to passive stretching of the left lower limb; AUZ, A1S, A1M, A3M. Shapiro-Wilk data normality test; and between moments.

"Note: Friedman test and after Dunn test. 


\section{DISCUSSION}

The present study showed a decrease in spasticity with the use of Ziclague associated with physiotherapy, being verified quantitatively by the Durigon Protocol and the Modified Ashworth Scale. It also demonstrated an increase in the range of motion quantified by dorsiflexion goniometry. One of the reasons for goniometry to show significance only in RLL, may be due to the functional predominance of a hemibody, which is due to the dominance of a cerebral hemisphere, being called laterality. This laterality may have influenced the results in children with diparesis and spastic tetraparesis, since it results in a predominance of the lesion in a hemibody ${ }^{(17)}$. With this there is a possibility that the increase in the dorsiflexion ROM in the RLL is due to the predominance of motor impairment and consequently greater severity of spasticity in LLL.

Elastic hypertonia of the triceps surae muscle is present in patients with upper motoneuron injury, including with $\mathrm{CP}$, a fact that generates tension imbalance between the plantar flexor and dorsiflexor muscles. With this imbalance, muscle shortening and even contractures can occur and thus the foot remains equine, that is, plantar flexion ${ }^{(18)}$. Since the triceps surae is the main muscle that promotes plantar flexion, the decrease in its tone leads to an increase in ROM of the ankle for dorsiflexion, justifying the results found here ${ }^{(19)}$.

Thinking that, to increase the ROM, it is necessary to decrease the spasticity of the antagonist muscle, the use of Ziclague allows this decrease. This is due to its 1.8 cineole and terpinene-4-ol, which promote muscle relaxation ${ }^{(20)}$. And also for its inotropic effect on the muscles through the inhibition of the $\mathrm{Ca}^{2+}$ of $\mathrm{L}$ type ${ }^{(21)}$, because in the spastic muscles there is hyperactivity of these channels, resulting in chronic inadequate regulation of the channels in the sarcoplasmic reticulum ${ }^{(22)}$. Thus, the use of Ziclague allows the reduction of spasticity by improving the regulation of these channels in spastic muscles, as shown in the present study. After the use of Ziclague, muscle relaxation was evidenced, which made it possible to increase ROM in a secondary way.

The spasticity of the triceps surae muscle was quantified by the Durigon Protocol and the Modified Ashworth Scale. Both scales showed a decrease in spasticity, but the Durigon Protocol showed greater sensitivity, which may be due to its graduation being through the rapid and slow passive mobilization of the joint ${ }^{(16)}$. Although the Ashworth Scale is the most cited in the literature for grading spasticity, both in adults and children ${ }^{(15)}$, it does not have specificity to detect small tonic changes ${ }^{(23)}$. Yam and Leung ${ }^{(24)}$ reported in their study the low reliability found on the
Ashworth Scale when quantifying the spasticity of children with $\mathrm{CP}$ and that the scale should be improved, since it is so sought after for the graduation of spasticity. This fact was also observed in the results found in this study, because despite the decrease in spasticity, the Modified Ashworth Scale was not sensitive to the point of reaching significance, unlike the Durigon Protocol, which determined significance in both lower limbs for decreasing spasticity of the triceps surae muscle.

In the scientific literature, other studies have also found the effectiveness of Ziclague in reducing spasticity in different sample profiles. As performed by Maia et al. ${ }^{(25)}$, with patients after stroke, mean age 43 years. They analyzed, through electromyography, the lateral and medial gastrocnemius muscles and verified an increase in the neuromuscular activity of the spastic muscles after the use of herbal medicine, showing a decrease in spasticity. In this way, it is possible to identify similar benefits for both adults and children, when using Ziclague.

Cândido et al. ${ }^{(13)}$, also used electromyography to assess spasticity in patients after stroke and spinal cord injury, comparing the control and study group, before and after the use of Ziclague associated with kinesiotherapy. 367 muscle groups were evaluated and after 10 intervention sessions, a decrease in neuromuscular activity was identified in the muscles evaluated.

A study similar to the present was carried out by Cândido and Xavier-Filho( ${ }^{(8)}$, also had children with spastic CP as a sample and used the Durigon Protocol for hypertension graduation. The children were separated into a study and control group and only the study group, in which the use of Ziclague by dermal or inhalation route was associated with kinesiotherapy, showed a decrease in the average graduation from 8 to 5 . In the group that performed only kinesiotherapy, there was no evident decrease in hypertonia. And although the present study did not present a control group, a fact that constitutes one of its limitations, both found a decrease in spasticity in children with CP submitted to treatment with Ziclague associated with physical therapy.

The beneficial results of Ziclague associated with physical therapy are also reaffirmed by studies carried out on animals. Cerqueira et al. ${ }^{(9)}$, analyzed four groups of rats after spinal cord injury, the first of which was just submitted to the application of herbal medicine, the second only to kinesiotherapy, the third underwent kinesiotherapy associated with herbal medicine and the fourth was not subjected to any interventions. In their results, it was evident that the group that associated kinesiotherapy with phytotherapy had a significant improvement 
regarding the decrease in spasticity, when compared to the other groups, mainly to control.

Thus, it is possible to infer that the use of the Ziclague herbal medicine provides beneficial effects to children with $\mathrm{CP}$, due to its antispasmodic action, resulting in decreased spasticity, increased neuromuscular activity and ROM. And the importance of the association with kinesiotherapy is evident so that its action is more effective.

\section{CONCLUSION}

It is concluded that the application of the herbal medicine Ziclague associated with physiotherapy provided beneficial effects. Its application resulted in a decrease in hypertonia in the triceps surae muscle, evidenced by both graduation scales and by an increase in dorsiflexion ROM. Thus, the use of Ziclague as a treatment strategy in support of physiotherapy for the reduction of hypertonia in children with spastic CP is reiterated.

\begin{abstract}
Authors' contributions: JSM defined the concept of the study, created the hypothesis and wrote the original proposal. JSM, MOG were involved in the critical review of the study proposal and the manuscript and Wrote this study protocol. All authors read and approved the manuscript.
\end{abstract}

Financial support: None declared.

Conflict of interest: The authors declare that there was no conflict of interests.

\section{REFERENCES}

1. dos Santos LPD, Golin MO. Evolução motora de crianças com paralisia cerebral diparesia espástica. Revista Neurociências. 2013;21(2):184-92.

2. Taboada-Lugo N, Quintero-Escobar K, Casamajor-Castillo M, González-Torres K, Marrero-Infante J, Cruz-Ubeda S, et al. Epidemiología de la parálisis cerebral en el Estado Plurinacional de Bolivia, 2009-2012. Revista Peruana de Epidemiología. 2013;17(2):1-7.

3. Righi NC, Martins FK, Souza JA, Trevisan CM. Distribuição da pressão plantar e morfologia do pé de crianças com paralisia cerebral e crianças com desenvolvimento típico. Fisioterapia e Pesquisa. 2017;24(3):321-6.

4. Miranda ERdAB, Palmieri $M$, Assumpção RMCd, Yamada HH, Rancan DR, Fucs PMdMB. Idade óssea na paralisia cerebral. Acta Ortopédica Brasileira. 2013;21(6):336-9.

5. dos Campos J. Perfil epidemiológico de crianças diagnosticadas com paralisia cerebral atendidas no Centro de Reabilitação Lucy Montoro de São José dos Campos. CEP. 2015;12220:280.

6. Tancredo JR, Maria RM, Azevedo ERFBM, Alonso KC, Varoto R, Cliquet Junior A. Análise clinica da espasticidade em indivíduos com lesão medular. Acta Ortopédica Brasileira. 2013;21(6):310-4.

7. Shamsoddini A, Amirsalari S, Hollisaz M-T, Rahimnia A, Khatibi-Aghda A. Management of spasticity in children with cerebral palsy. Iranian journal of pediatrics. 2014;24(4):345.

8. Cândido EAF, Xavier-Filho L. Viabilidade do uso do óleo essencial da Alpinia zerumbet, Zingiberaceae, na otimização do tratamento fisioterapêutico em paralisia cerebral espástica. Arquivos Brasileiros de Neurocirurgia: Brazilian Neurosurgery. 2012;31(03):110-5.

9. de Cerqueira FL, de Albuquerque Junior RLC, Zini CA, Caramao EB, Cândido EAF. Efeitos da cinesioterapia associada ao bioproduto à base do óleo essencial da Alpinia zerumbet sobre o colágeno dos tecidos musculares espásticos de ratos pós-lesão medular. InterSciencePlace. 2016;10(4).

10. Cândido EAF, Freitas MM, Cândido JF, de Cerqueira FL. Nova alternativa tecnológica para medicamento direcionado à espasticidade. Revista Ibero-Americana de Ciências Ambientais. 2013;4(2):119-26.

11. Pinto WBVdR. Ziclague. (Alpinia zerumbet). In: Paulo UFdS, editor. 2017.

12. Cândido JF, dos Santos Meneses DC, de Carvalho-Neto JN, Xavier-Filho L, Cândido EAF. Subacute and Chronic Treatment with Herbal Medicine Essential Oil the Alpinia Zerumbet Associated with Kinesiotherapy on Patient with Muscle Spasticity: Cases Series. International Journal of Research Studies in Biosciences 2017b. 2017;5(9):1-6.

13. Cândido JF, de Andrade Lopes RM, Xavier-Filho L, Cândido EAF. Influence of Alpinia zerumbet essencial oil in the kinesiotherapeutic treatment os patients with syndrome piramidal. International Journal os Development Research 2017a. 2017;7(10):15837-43.

14. Marques AP. Manual de goniometria: Editora Manole; 1997.

15. de Mello Sposito MM, Riberto M. Avaliação da funcionalidade da criança com Paralisia Cerebral espástica. Revista Acta Fisiátrica. 2010;17(2):50-61.

16. Durigon O, Sá C, Sitta L. Validação de um protocolo de avaliação do tono muscular e atividades funcionais para crianças com paralisia cerebral. Revista neurociências. 2004;12(2):87-93. 
17. Smith LR, Pontén E, Hedström Y, Ward SR, Chambers HG, Subramaniam S, et al. Novel transcriptional profile in wrist muscles from cerebral palsy patients. BMC medical genomics. $2009 ; 2(1): 44$.

18. Yang Y, Xiao J, Song W. Post-activation depression of the lower extremities in stroke patients with spasticity and spastic equinovarus deformity. Arquivos de neuro-psiquiatria. 2015;73(6):493-8.

19. de Oliveira LdS, Golin MO. Técnica para redução do tônus e alongamento muscular passivo: efeitos na amplitude de movimento de crianças com paralisia cerebral espástica. ABCS health sciences. 2017;42(1).

20. Freitas J, Costin ACMS, Mélo TR. Avaliação psicomotora de crianças com paralisia cerebral deambuladoras: aplicabilidade. caracterização 2018;17(3):322.

ConScientiae Saúde.

21. Santos B, Roman-Campos D, Carvalho $M$, Miranda F, Carneiro D, Cavalcante $P$, et al. Cardiodepressive effect elicited by the essential oil of Alpinia speciosa is related to L-type $\mathrm{Ca} 2+$ current blockade. Phytomedicine. 2011;18(7):539-43.
22. Ferreira MER, Cândido EAF, Freitas MM. Análise das alterações histopatológicas e comportamental em modelo experimental de traumatismo raquimedular em tratamento agudo e subagudo com o uso do Ziclague ${ }^{\circledR}$. Semana de Pesquisa da Universidade TiradentesSEMPESq. 2018(18).

23. Junior Aap, Butzke J, Persuhn Jj. Aplicação Do Kinesio Taping ${ }^{\circledR}$ Associado À Cinesioterapia $\mathrm{Na}$ Correção da Marcha Pós Acidente Vascular Encefálico. Revista Pesquisa Em Fisioterapia. 2016;6(1).

24. Yam WKL, Leung MSM. Interrater reliability of Modified Ashworth Scale and Modified Tardieu Scale in children with spastic cerebral palsy. Journal of child neurology. 2006;21(12):1031-5.

25. Maia MON, Dantas CG, Xavier Filho L, Cândido EAF, Gomes MZ. The Effect of Alpinia zerumbet Essential Oil on Post-Stroke Muscle Spasticity. Basic \& Clinical Pharmacology \& Toxicology. 2016;118(1):58-62. 